\title{
Influence of microwave-assisted chemical treatment on delignification of rice straw biomass
}

\author{
Bhat, M.I. ${ }^{1}$, Shahi, N.C. ${ }^{2}$, Lohani, U. C. ${ }^{3}$, Kumar, A. ${ }^{4}$, Malik, S. ${ }^{1}$
}

Received: 19.03.2021

Revised: 12.04.2021

Accepted: 24.04.2021

\begin{abstract}
Lignocellulosic biomass (like rice straw) provides an alternative for depleting non-renewable energy sources through its value-added utilization (like production of biofuels and nanocellulose) owing to its abundance, renewability, polymer presence and environmental friendliness. Prior to its utilization, any lignocellulosic biomass is subjected to a timeconsuming delignification process for lignin free biomass recovery. The present study aims to reduce the time of delignification of rice straw along with enhancing the delignification percentage of biomass by use of microwave assisted sodium chlorite method. The experiments were done at two microwave power levels $(640,800 \mathrm{~W})$, three bleaching solution concentrations $(0.4,1.7,3.0 \%)$ and three microwave treatment times $(4,8,12 \mathrm{~min})$. The delignification percentage of the rice straw for the whole experimentation varied from 24.7 to $90.12 \%$. The results revealed that the time of delignification was greatly reduced $(12 \mathrm{~min})$ with a very high delignification $(90.12 \%)$ percentage. The morphology of the delignified samples also revealed the deconstruction of the lignin structure. The improved method can thus be applied for the delignification of other biomasses as well for quick and effective delignification.
\end{abstract}

Key words: Delignification Percentage, Bleaching, Lignocellulosic biomass, Microwave assisted chemical treatment, Rice straw, Sodium Chlorite

\section{Introduction}

In the contemporary world of environmental concern due to fossil fuel depletion and increased carbon footprint (Sain et al., 2020), more emphasis has been laid on conventional and value-added nonconventional utilization of lignocellulosic biomass (Saratale, 2012). Lignocellulosic biomass refers to the plant dry matter which plays an important role in the carbon cycling process. It embodies a wide spectrum of materials ranging from agricultural wastes, forest residues, industrial by-products, to energy crops, primary crop residues, etc. with a global annual production of 181.5 billion tons and energy value between 5 and $50 \mathrm{EJ} /$ year (Kang et al., 2014; Maurya et al., 2015; Paul and Dutta, 2018). Conventionally, lignocellulosic biomass has been used for the production of biofuels, bioethanol, grafted polymers, platform chemicals apart from its unscientific burning which causes secondary environmental pollution (Bozell et al., 2011; Kang et al., 2014; Mukherjee et al., 2018;

\section{Author's Address}

$1,2 \& 3$ Department of Post-Harvest Process \& Food Engineering, GBPUAT, Uttarakhand, India.

${ }^{4}$ Department of Food Science \& Technology, GBPUAT, Uttarakhand, India.

E-mail.: bhatmohammadishfaq@gmail.com
Zheng et al., 2014; Sain, 2020). With the advent of nanoscience and nanotechnology, a revolutionary concept, the lignocellulosic biomass has been utilized non-conventionally by its miniaturization to nano-scale (Lee et al., 2014; Yu et al., 2021). Before both conventional and non-conventional utilization of lignocellulosic biomass, delignification is the most important step for obtaining lignin-free holocellulose (cellulose and hemicellulose) (Jin et al., 2019). Several methods have been reported in the literature for the delignification of lignocellulosic biomass (Kucharska et al., 2018). The still considered and the most effective method is the acidified sodium chlorite delignification (Kumar et al., 2013). However, the procedure is time-consuming and the lignin is not removed completely in most of cases due to the recalcitrant nature of the lignocellulose. To speed up the process and enhance lignin removal, microwave-assisted delignification has been used (Kohli et al., 2020; Liu et al., 2017). Microwaves possess innate ability in presence of moisture (dipoles or ions) to open up the structure of the cell walls and make the components available for subsequent reaction (Nour et al., 
2021). Rice stands to be the largest produced cereal crop globally, with a production of 782 million tonnes in 2018 and increasing by almost $1.8 \%$ yearly. (FAOSTAT, 2020). In rice production, the volumetric percentage of rice straw is about $45 \%$, and is quantitatively the highest crop residue ( $\mathrm{Lu}$ and Hsieh, 2012). Each $\mathrm{kg}$ of milled rice produced results in roughly $0.7-1.4 \mathrm{~kg}$ of rice straw depending on varieties, cutting height of the stubbles, and moisture content during harvest (IRRI, 2020). Rice straw residue has been utilized for the production of biofuels, grafted polymer fermentable sugars as well as for production of novel nanocellulose preceded by an essential delignification step, which can be enhanced by microwaves to improve the purity of final product (Lu and Hsieh, 2012; Mukherjee et al., 2018; Oun and Rhim, 2016, 2018). The present study was aimed to improve the speed and effectiveness of delignification of rice straw biomass by microwave-assisted chemical treatment.

\section{Materials and Methods}

The experiments were carried out at the Department of Post-Harvest Technology, GBPUAT, Pantnagar, Uttarakhand, India. Rice straw was collected from the Crop Research Centre of the university. Standard chemicals including ethanol, toluene, sodium chlorite, and glacial acetic acid, nitric acid were used in the experiment.

\section{Experimental Procedure}

The initial composition of the rice straw viz. moisture content, oven-dry solids, extractives, and lignin were determined using standard procedures reported in the literature (Sluiter et al., 2008a; Sluiter et al., 2012; Sluiter et al., 2008b). The biomass recovered was calculated based on the weight difference method (initial solid weight minus extractives and lignin). The experimentation was done using dewaxed rice straw powder (RSP) of a particular size. The dewaxing was done for extractive removal as reported by ( $\mathrm{Lu}$ and Hsieh, 2012). The rice straw was first thoroughly washed with tap water to remove dust particles before being washed with distilled water. This was followed by drying at $105{ }^{\circ} \mathrm{C}$ for $24 \mathrm{hrs}$. The dried rice straw was then ground using a hammer mill and sieved to get a powder size of $300 \mu \mathrm{m} .30 \mathrm{~g}$ rice straw powder (RSP) was dewaxed (by refluxing method) with a $450 \mathrm{ml}$ mixture of ethanol/toluene $(1: 2)$ for $20 \mathrm{~h}$. This was followed by vacuum filtration of the sample and subsequent drying in the oven at $50{ }^{\circ} \mathrm{C}$ for $5 \mathrm{~h}$ to remove the left-over ethanol or toluene. The dewaxed sample ( $10 \mathrm{~g}$ for each sample) was then subjected for delignification using microwaveassisted acidified sodium chlorite method. Two microwave power levels (640 and $800 \mathrm{~W})$, three concentrations of sodium chlorite solution $(0.4,1.7$, and $3.0 \%$ ), and three microwave treatment times $(4,8$, and $12 \mathrm{~min})$ were used in the experiment. The $\mathrm{pH}$ of the sodium chlorite solution was adjusted to 3.9 using 5\% glacial acetic acid solution. A single charge of sodium chlorite was used in a particular experiment. Immediately after treating the sample (in the solution of acidified sodium chlorite) by microwaves for a particular duration, the reaction was quenched using a copious amount of ice-cold distilled water. The solution was repeated filtered (using Whatman Glass Fibre filter, 934-AH, Cat No. 1827047) and washed with distilled until the filtrate became $\mathrm{pH}$ neutral. The delignified biomass obtained was then carefully removed and dried until constant weight. The weight of each sample was recorded and the amount of lignin removed was obtained by the weight difference method as given by Equation 1.1. The schematic representation of the various steps in the experiment is depicted in Figure.1

$$
\% \text { Delignification }=\frac{M_{i}-M_{f}}{L_{i}} \times 100 \quad \mathbf{1 . 1}
$$

Where,

$M_{i}$ and $M_{f}$ - Initial and final mass of the sample (before and after delignification)

$\mathrm{L}_{\mathrm{i}}$ - Amount of lignin initially present in the sample

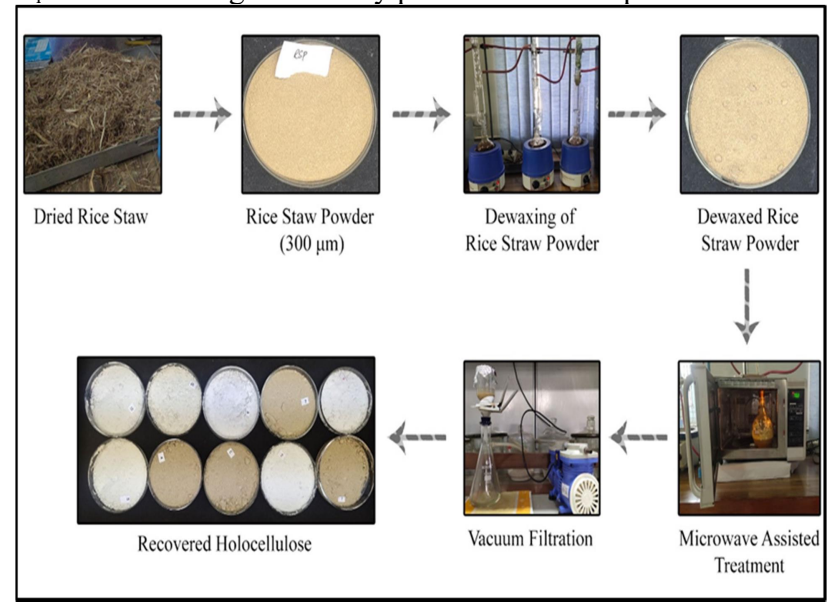

Figure 1: Schematic flowchart of the experimental procedure 


\section{Results and Discussion}

The present study aimed to reduce the time required for delignification of rice straw biomass and also enhance the effectiveness of cleaving the lignin bonding using a microwave-assisted approach. Different experimental conditions were tested in the study. The initial composition of the rice straw revealed the results shown in Table 1.The results are congruent with those reported in previous literature (Cheng et al., 2011; Dutta et al., 2014; Yadav et al., 2016). Variations in the initial composition pertained to the difference in variety, geographical conditions and cultivars. After subjecting the dewaxed rice straw powder to microwave treatment, the colour of the samples changed from brownish to light brownish and white (for different experimental conditions) as shown in Figure 2. The change of colour signifies the removal of lignin from the dewaxed rice straw powder. At lower concentrations of sodium chlorite solution $(0.4 \%)$, the colour changed to light brown, which signified the presence of residual lignin, while in the case of other concentrations (1.7 and $3.0 \%)$ the colour was off-white and white respectively.
The delignification percentage (DP) achieved after the microwave treatment at different experimental conditions is shown in Table 2. The DP of rice straw biomass in the present study varied from 24.7 to $90.12 \%$. The results signified that the application of microwave-assisted method was successful in delignifying the samples effectively and quickly. The graphs of the results at two microwave powers are shown in Figures 3 and 4.

Table 1. Initial Composition of the rice straw

\begin{tabular}{|c|l|c|}
\hline $\begin{array}{c}\text { S. } \\
\text { No }\end{array}$ & \multicolumn{1}{|c|}{ Composition } & $\begin{array}{c}\text { Average } \\
\text { Value (\%) }\end{array}$ \\
\hline $\mathbf{1 .}$ & Moisture Content & 9.99 \\
\hline $\mathbf{2 .}$ & Extractives & 7.51 \\
\hline $\mathbf{3 .}$ & $\begin{array}{l}\text { Acid Soluble } \\
\text { Lignin }\end{array}$ & 3.86 \\
\hline $\mathbf{4 .}$ & $\begin{array}{l}\text { Acid Insoluble } \\
\text { Lignin (Klason- } \\
\text { Lignin) }\end{array}$ & 10.83 \\
\hline $\mathbf{5 .}$ & Cellulose & 34.31 \\
\hline $\mathbf{6 .}$ & Hemicellulose & 31.70 \\
\hline
\end{tabular}

Table 2. Delignification percentage at different experimental conditions

\begin{tabular}{|c|c|c|c|c|}
\hline Microwave Power (Watt) & \multicolumn{1}{|c|}{$\begin{array}{c}\text { Irradiation Time } \\
\text { (Minutes) }\end{array}$} & \multicolumn{2}{|c|}{$\begin{array}{c}\text { Percent Delignification (\%) } \\
\text { (Based on initial amount of lignin) }\end{array}$} \\
\hline \multirow{2}{*}{} & & \multicolumn{2}{|c|}{ Bleaching Solution Concentration } \\
\hline \multirow{2}{*}{800} & 4 Min & $\mathrm{C}_{1}(0.4 \%)$ & $\mathrm{C}_{2}(1.7 \%)$ & $\mathrm{C}_{3}(3.0 \%)$ \\
\hline \multirow{2}{*}{80} & 26.7 & 56.43 & 78.76 \\
\cline { 2 - 5 } & $8 \mathrm{Min}$ & 26.9 & 59.32 & 85.91 \\
\cline { 2 - 5 } & $12 \mathrm{Min}$ & 27.5 & 63.11 & 90.12 \\
\hline \multirow{2}{*}{640} & $4 \mathrm{Min}$ & 24.7 & 50.12 & 66.54 \\
\cline { 2 - 5 } & $8 \mathrm{Min}$ & 25.9 & 52.33 & 74.21 \\
\cline { 2 - 5 } & $12 \mathrm{Min}$ & 26.5 & 60.17 & 88.21 \\
\hline
\end{tabular}




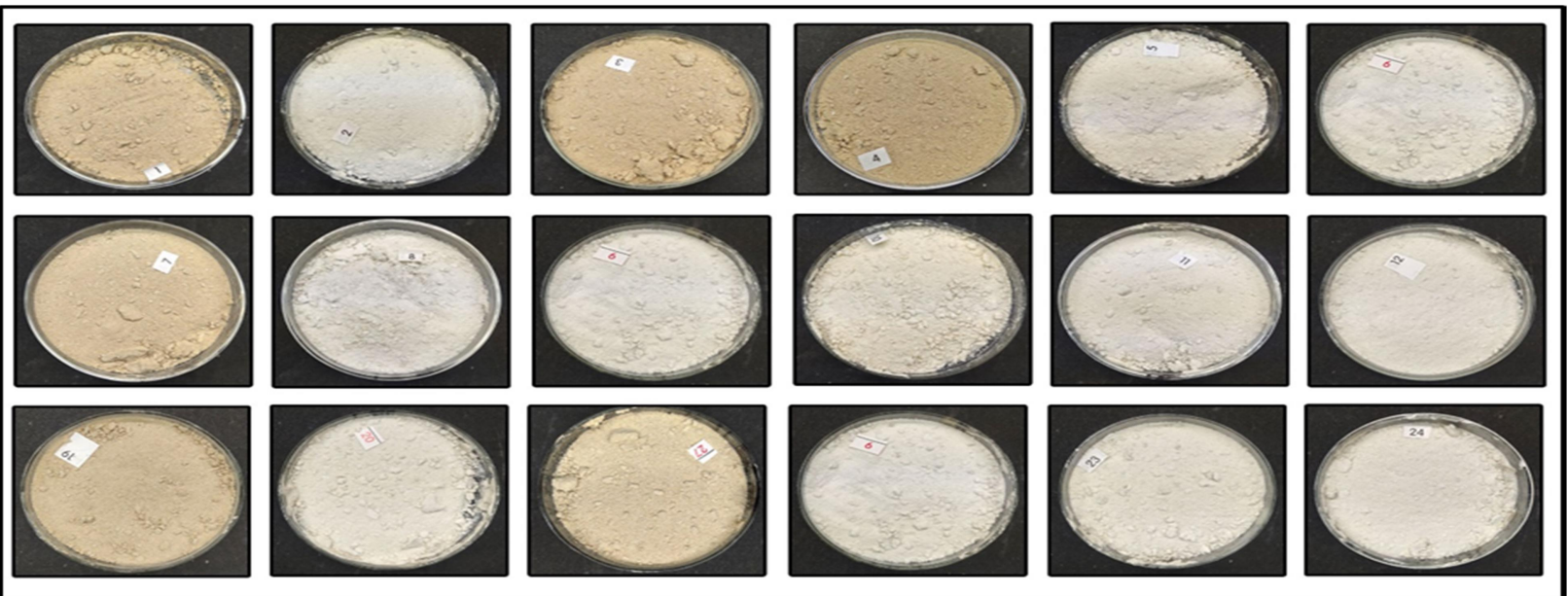

Figure 2: Differential change in colour of dewaxed rice straw powder after microwave assisted chemical treatment at different conditions

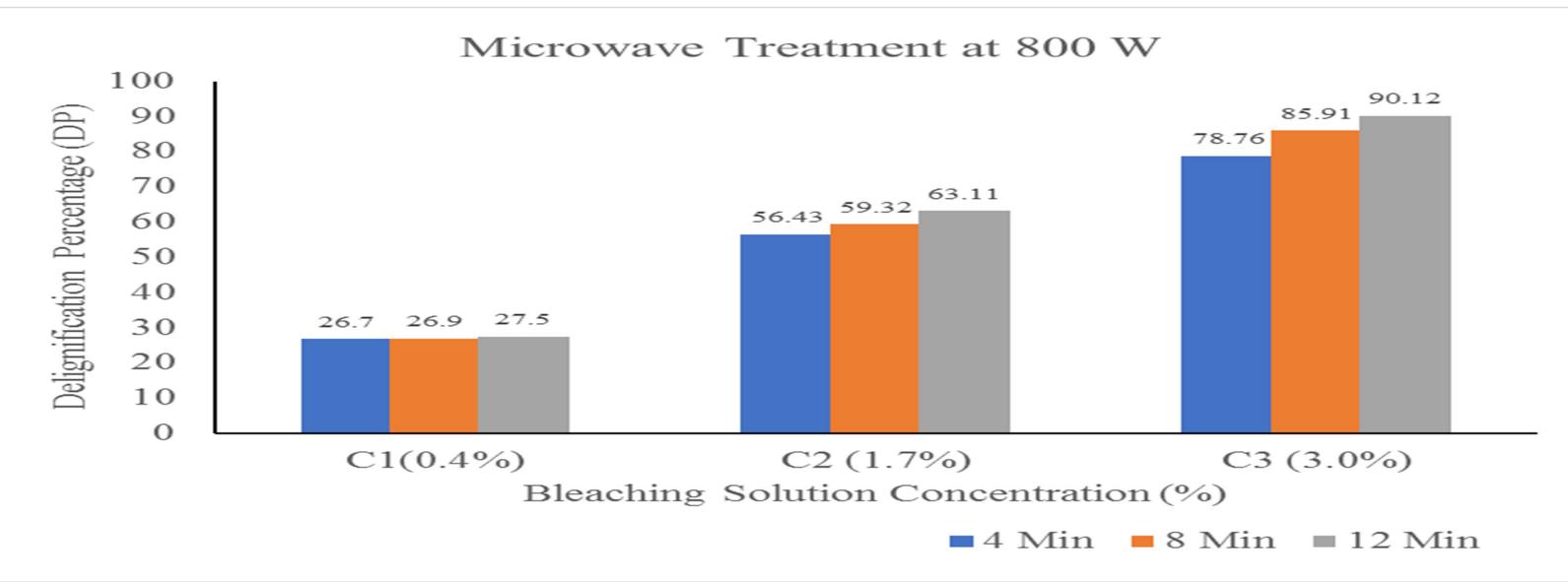

Figure 3: Delignification Percentage at Microwave Treatment of $800 \mathrm{~W}$

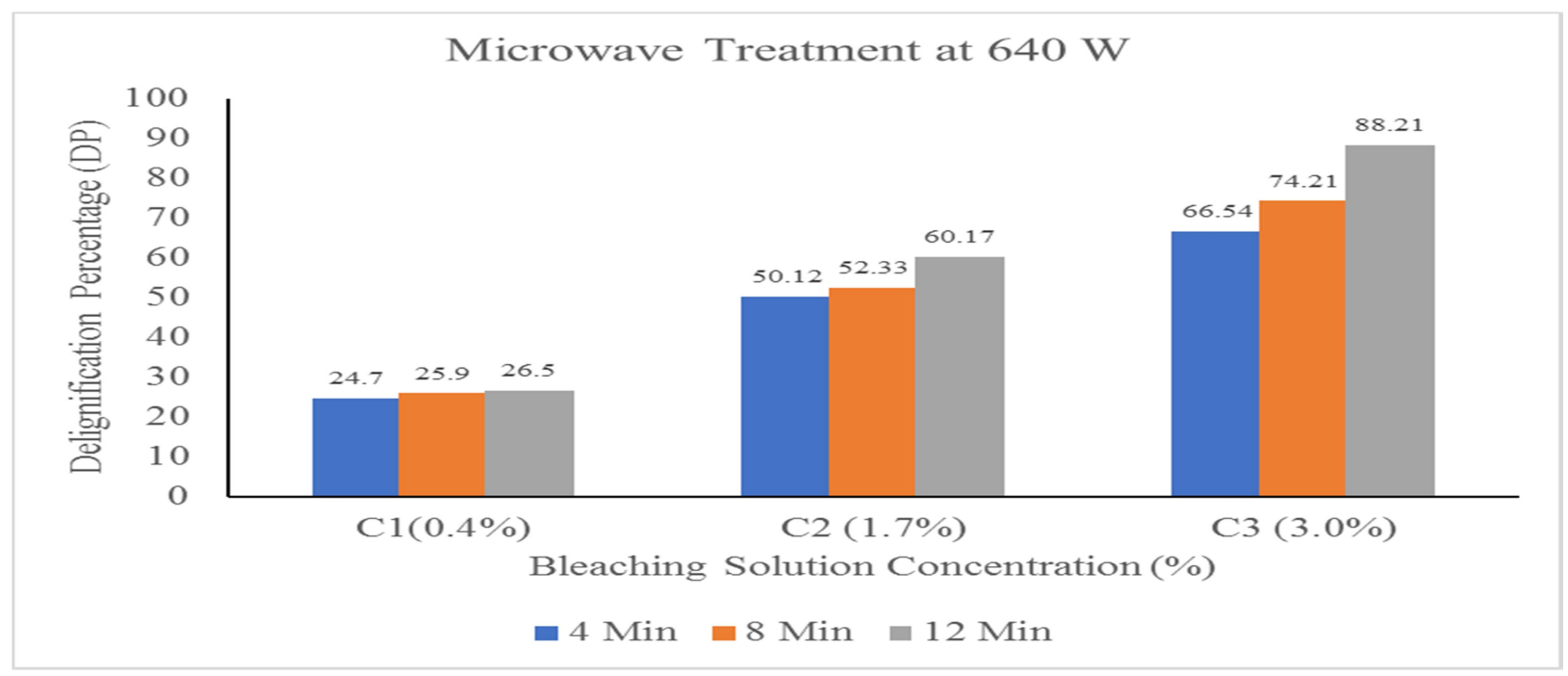

Figure 4: Delignification Percentage at Microwave Treatment of $640 \mathrm{~W}$ 
Effect on Microwave power, Irradiation time and Bleaching Solution Concentration on the Delignification of Rice Straw

The effect of microwave power on the delignification can be seen from figures 2 and 3. At $640 \mathrm{~W}$, the delignification percentage varied from 24.7 to $88.21 \%$ for different concentrations and irradiation times, while at $800 \mathrm{~W}$, the delignification percentage varied from 26.7 to $90.12 \%$. The delignification percentage achieved in this study was comparable and even better than the results obtained for delignification of various lignocellulosic biomasses like red meranti woodsaw dust $(97 \%)$, maize straw $(78.0 \%)$, rye straw $(68.8 \%)$, rice straw $(82.1 \%)$ using conventional sodium chlorite and other bleaching methods for long durations with multiple charges (Noredyani et al., 2020; Xiao et al., 2001). (Kumar et al., 2013) achieved delignification of $90-95 \%$ using conventional sodium chlorite bleaching (with three charges of sodium chlorite) method in switchgrass, poplar, corn stover, and pine sawdust. Regarding microwave-assisted treatment, 40 and $80 \%$ delignification was achieved by microwave-assisted water and peracetic acid treatment of pineapple waste (Azelee et al., 2019). The results confirmed the disruption of lignin-carbohydrate complex and effective delignification due to application of microwaves. Also, delignification of rice husk by microwave-assisted treatment at 240 watts resulted in almost $30 \%$ delignification in just 5 minutes (Laghari et al., 2018). The effect of microwaves is due to the enhanced cell wall rupture and subsequent diffusion caused by unidirectional inside out heat and mass transfers (Veggi et al., 2013). On increasing the microwave power from 640 to $800 \mathrm{~W}$ the increase in delignification percentage was achieved more at higher concentrations and less at lower concentrations as seen in figures 2 and 3. Similar results were reported by (Azelee et al., 2019) where optimized microwave-assisted water and peracetic acid delignification was achieved at 750 and 550 watts respectively. The results showed that on increasing microwave power, the delignification increased in both cases, an optimum of $550 \mathrm{~W}$ and $750 \mathrm{~W}$ for water and peracetic acid respectively, which confirms the results of this study. The change in concentration had a profound effect on the delignification percentage of rice straw. On increasing the concentration from $0.4 \%$ to $3.0 \%$, the delignification percentage increased from 24.7 to $88.21 \%$ and 26.7 to $90.12 \%$ for microwave powers of 640 and $800 \mathrm{~W}$ respectively. Conventional sodium chlorite bleaching of lignocellulosic biomass has shown same or lower delignification percentages but with higher concentration and number of charges of sodium chlorite. The difference is because the availability of lignin for removal is more due to the application of microwaves which destroys the structure and makes the lignin of both the lumen and middle lamella available for the bleaching solution (Siqueira et al., 2013). Delignification percentage of about $97 \%$ was achieved for red meranti sawwood powder but at a concentration of $25 \%$ sodium chlorite using the conventional water bath heating method (Noredyani et al., 2020). Park et al. (2015) delignified mixed hardwood chip powder through conventional hot water bath bleaching using $41 \%$ sodium chlorite with a percentage delignification of about $77 \%$ albeit addition of five to six charges each hour. Laghari et al. (2018) found that on subjecting rice husk to microwaveassisted chemical treatment (with sodium hydroxide, sodium carbonate, hydrogen peroxide and sulfuric acid) the delignification percentage increased by increasing the concentration from 2 to $5 \%$, except for sodium hydroxide where the maximum delignification of about $43 \%$ was seen at $3.5 \%$ concentration and this being highest of all the treatments. Thus, in the present study, a clear reflection of a synergistic effect on the increase in delignification percentage due to application microwaves and increased concentration of sodium chlorite is seen. Due to the application of microwaves, the time of delignification has significantly reduced to 12 minutes as compared to the time (almost $6 \mathrm{~h}$ or more) required for the same or less percentage of delignification at higher concentration in conventional sodium chlorite bleaching process (Jin et al., 2019; Kohli et al., 2020; Kucharska et al., 2018; Kumar et al., 2013). Subhedar and Gogate (2014) delignified newspaper waste using sodium hydroxide and got a delignification percentage of about $80.0 \%$ and $40.2 \%$ with and without the use of ultrasound at a time duration of $70 \mathrm{~min}$ and $6 \mathrm{~h}$ respectively. Thus, the use of microwave-assisted chemical treatment greatly reduces the time of the bleaching process. 
Similar results for reduction in bleaching time (up to $10-15 \mathrm{~min}$ ) using microwave-assisted treatment has been reported in literature (Azelee et al., 2019). The time reduction for bleaching using microwaveassisted alkaline, organosolv, sodium chlorite, ionic liquid and acetosolv treatment has been reported in literature (Akhtar et al., 2014; Avelino et al., 2019; Shengdong et al., 2005; Sun et al., 2019; Yaakob et al., 2020). The effect of varying microwave irradiation time or treatment time also has a significant effect on variation of delignification percentage. However, the difference at the lower concentrations is not highly significant as compared to the higher concentration at both the microwave powers. At $640 \mathrm{~W}$, the delignification percentage change was about $1.8 \%$ in going from 4 to $12 \mathrm{~min}$ as compared to only $0.8 \%$ for same time increase for $800 \mathrm{~W}$. Similar pattern can be seen at higher sodium chlorite solution concentrations of 1.7 and $3.0 \%$. This is probably because, there is a gradual

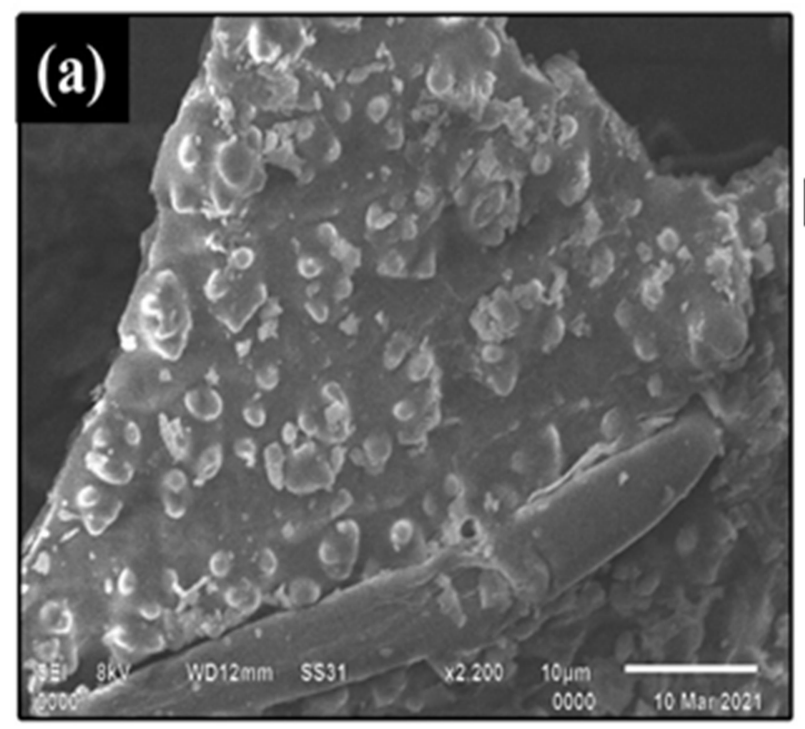

lignin-carbohydrate complex breakdown at lower microwave power than at higher microwave power which results in quick consumption of lignin at higher microwave power with little difference or changes with time at the same concentration as compared to that at lower microwave power.

The microstructure of the rice straw powder and the delignified rice straw sample (with the highest delignification percentage of $90.12 \%$ ) was evaluated through the scanning electron microscope (SEM). The SEM images of both the rice straw powder and the delignified sample are shown in Figure $5(\mathrm{a} \& \mathrm{~b})$. It is quite clear from the images, that, initially (Fig.5a) the surface of the rice straw powder is packed and smooth, which is due to the closed and complex structure formed by lignin with cellulose and hemicellulose. However, on delignification (fig. 5b), due to the lignincarbohydrate cleavage and removal of lignin a more porous and rough structure can be seen.

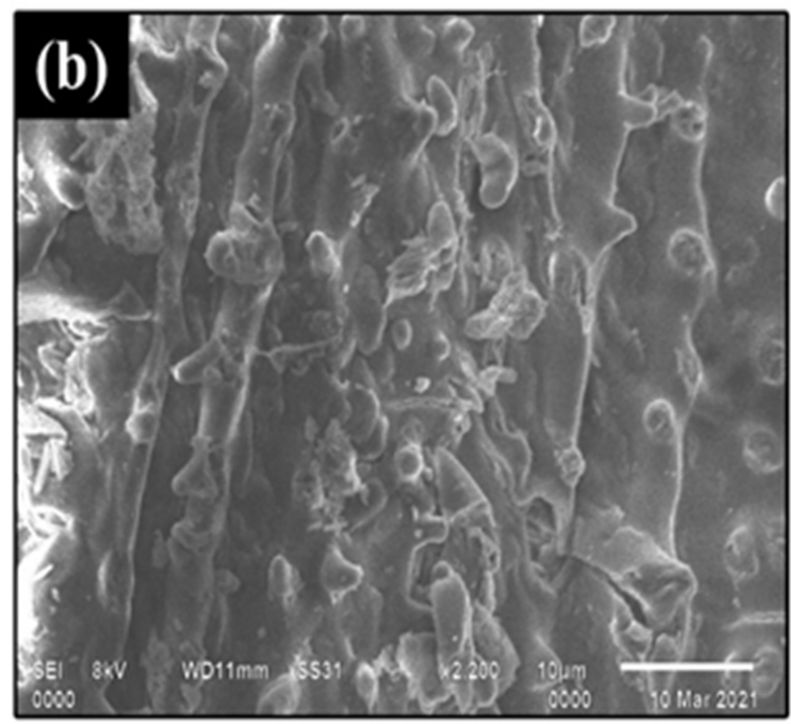

Figure 5. Scanning electron microscope image (a) Rice straw powder (b) Delignified rice straw powder

\section{Conclusion}

In the present study, Microwave-assisted chemical treatment of rice straw led to its quick and effective delignification. The quick and intense delignification of the rice straw with a single charge of sodium chlorite (as compared to multiple charges used in conventional sodium chlorite deligni- fication) directly reduces the energy use along with the amount of chlorine generated in the

process. This reduces the impact on the environment and subsequently the carbon footprint. Besides this, both the aforementioned facts have the potential of cost reduction in the scale-up mode. 
The experiments conducted revealed that the delignification percentage varied from 24.7 to $90.12 \%$ for the experimental conditions. The maximum delignification percentage was obtained at microwave power, irradiation time and bleaching solution concentration of $800 \mathrm{~W}, 12 \mathrm{~min}$ and $3.0 \%$ respectively. Moreover, the microstructure of the delignified sample revealed the disruption of lignincarbohydrate complex and removal of lignin. The process can further be taken for optimization using a wider parameter range and in-depth character-

\section{References}

Akhtar, J., Teo, C. L., Lai, L. W., Hassan, N., Idris, A. and Aziz, R. A. 2014. Factors Affecting Delignification of Oil Palm Empty Fruit Bunch by Microwave-assisted Dilute Acid/Alkali Pretreatment. BioResources. 2014, 10(1),

Avelino, F., Marques, F., Soares, A. K. L., Silva, K. T., Leitão, R. C., Mazzetto, S. E. and Lomonaco, D. 2019. Microwave-Assisted Organosolv Delignification: A Potential Eco-Designed Process for Scalable Valorization of Agroindustrial Wastes. Industrial \& Engineering Chemistry Research, 58(25), 10698-10706. doi:10.1021/acs.iecr.9b01168

Azelee, N. I. W., Adnan, S. A. M., Manas, N. H. A., Dailin, D. J., Ramli, A. N. M. and Illias, R. M. 2019. Assessment of microwave-assisted pretreatments for enhancing pineapple waste delignification. Proceedings of the 2nd International Conference on Biosciences and Medical Engineering (ICBME2019) AIP Conf. Proc. 2155, 020003-1-020003-6; https://doi.org/10.1063/1.5125507

Bozell, J. J., Black, S. K., Myers, M., Cahill, D., Miller, W. P. and Park, S. 2011. Solvent fractionation of renewable woody feedstocks: Organosolv generation of biorefinery process streams for the production of biobased chemicals. Biomass and Bioenergy, 35(10), 4197-4208. doi:https://doi.org/10.1016/j.biombioe.2011.07.006

Cheng, J., Su, H., Zhou, J., Song, W. and Cen, K. 2011. Microwave-assisted alkali pretreatment of rice straw to promote enzymatic hydrolysis and hydrogen production in dark- and photo-fermentation. International Journal of

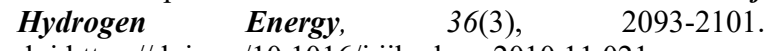
doi:https://doi.org/10.1016/j.ijhydene.2010.11.021

Dutta, S. K., Halder, G. and Mandal, M. K. 2014. Modeling and optimization of bi-directional delignification of rice straw for production of bio-fuel feedstock using central composite design approach. Energy, 71, 579-587. doi:https://doi.org/10.1016/j.energy.2014.04.108

FAOSTAT. 2020. FAO Statistical Databases. Retrieved from http://www.fao.org/faostat/en/\#data/QC. 22 November 2020 ization of delignified samples could be done.

\section{Acknowledgements}

The present study was granted funding by Technical Education Quality Improvement Programme (TEQIP-III), operational at College of Technology, GBPUAT, Pantnagar. Special thanks to my beloved parents, siblings and my wife Mrs. Muftisa for constant support during the experimentation and preparation of this manuscript.

IRRI. 2020. RIce by-products: In Post Production of Rice. Retrieved from http://www.knowledgebank.irri.org/stepby-step-production/postharvest/rice-by-products. 08-022021

Jin, K., Liu, X., Jiang, Z., Tian, G., Yang, S., Shang, L. and Ma, J. 2019. Delignification kinetics and selectivity in poplar cell wall with acidified sodium chlorite. Industrial Crops and Products, 136, 87-92. doi:https://doi.org/10.1016/j.indcrop.2019.04.067

Kang, Q., Appels, L., Tan, T. and Dewil, R. 2014. Bioethanol from Lignocellulosic Biomass: Current Findings Determine Research Priorities. The Scientific World Journal, 2014, 298153. doi:10.1155/2014/298153

Kohli, K., Katuwal, S., Biswas, A. and Sharma, B. K. 2020. Effective delignification of lignocellulosic biomass by microwave assisted deep eutectic solvents. Bioresource Technology, 303, 122897. doi:https://doi.org/10.1016/j.biortech.2020.122897

Kucharska, K., Rybarczyk, P., Hołowacz, I., Łukajtis, R., Glinka, M. and Kamiński, M. 2018. Pretreatment of Lignocellulosic Materials as Substrates for Fermentation Processes.Molecules, 23(11), 2937.

Kumar, R., Hu, F., Hubbell, C. A., Ragauskas, A. J. and Wyman, C. E. 2013. Comparison of laboratory delignification methods, their selectivity, and impacts on physiochemical characteristics of cellulosic biomass. Bioresource Technology, 130, 372-381. doi:https://doi.org/10.1016/j.biortech.2012.12.028

Laghari, S. M., Tunio, M. M., Laghari, A. Q., Laghari, A. J. and Ali, A. M. 2018. Delignification of Rice Husk by Microwave Assisted Chemical Pretreatment. Engineering, Technology \&amp; Applied Science Research, 8(3), 30843087. doi:10.48084/etasr.2143

Lee, H. V., Hamid, S. B. A. and Zain, S. K. 2014. Conversion of Lignocellulosic Biomass to Nanocellulose: Structure and Chemical Process. The Scientific World Journal, 2014, 631013. doi:10.1155/2014/631013 


\section{Bhatt et al.}

Liu, Y., Chen, W., Xia, Q., Guo, B., Wang, Q., Liu, S., Liu, Y., $\mathrm{Li}$, J. and $\mathrm{Yu}, \mathrm{H}$. 2017. Efficient Cleavage of LigninCarbohydrate Complexes and Ultrafast Extraction of Lignin Oligomers from Wood Biomass by MicrowaveAssisted Treatment with Deep Eutectic Solvent. ChemSusChem, 10(8), 1692-1700.

Lu, P. and Hsieh, Y.-L. 2012. Preparation and characterization of cellulose nanocrystals from rice straw. Carbohydrate Polymers, 87(1), 564-573.

doi:https://doi.org/10.1016/j.carbpol.2011.08.022

Maurya, D. P., Singla, A. and Negi, S. 2015. An overview of key pretreatment processes for biological conversion of lignocellulosic biomass to bioethanol. 3 Biotech, 5(5), 597609. doi:10.1007/s13205-015-0279-4

Mukherjee, A., Banerjee, S. and Halder, G. 2018. Parametric optimization of delignification of rice straw through central composite design approach towards application in grafting. Journal of Advanced Research, 14, 11-23. doi:https://doi.org/10.1016/j.jare.2018.05.004

Noredyani, A. R. S., Zularisam, A. W., Noormazlinah, A. and Sakinah, A. M. M. 2020. Optimization of Delignification Process from Red MerantiWood Sawdust (RMWS) Pretreated with Acidified Sodium Chlorite. In M. Awang, M. M. Emamian, andF. Yusof (Eds.), Advances in Material Sciences and Engineering (pp. 155-168):

Nour, A., Alara, O., Nour, A., Omer, M. and Ahmad, N. 2021. Microwave-Assisted Extraction of Bioactive Compounds (Review). In Microwave Heating (pp. 1-31): IntechOpen.

Oun, A. A. and Rhim, J. W. 2016. Isolation of cellulose nanocrystals from grain straws and their use for the preparation of carboxymethyl cellulose-based nanocomposite films. Carbohydrate Polymers, 150, 187200.doi:https://doi.org/10.1016/j.carbpol.2016.05.020

Oun, A. A. and Rhim, J. W. 2018. Isolation of oxidized nanocellulose from rice straw using the ammonium persulfate method. Cellulose, 25(4), 2143-2149. doi:10.1007/s10570-018-1730-6

Park, J., Shin, H., Yoo, S., Zoppe, J. and Park, S. 2015. Delignification of Lignocellulosic Biomass and Its Effect on Subsequent Enzymatic Hydrolysis. BioResources, 10, 2732-2743. doi:10.15376/biores.10.2.2732-2743

Paul, S. and Dutta, A. 2018. Challenges and opportunities of lignocellulosic biomass for anaerobic digestion. Resources, Conservation and Recycling, 130, 164-174. doi:https://doi.org/10.1016/j.resconrec.2017.12.005

Sain, M. 2020. Production of bioplastics and sustainable packaging materials from rice straw to eradicate stubble burning: A mini-review. Environment Conservation Journal, 21(3), 1-5. doi: http://dx.doi.org/10.36953/ECJ.2020.21301
Sain, M., Singh, A., Kaur, A., \& Zalpouri, R. (2020). Metaphysical energy based sustainable yogic farming for enhanced productivity and farmers' well being: A Review. Environment Conservation Journal, 21(3), 6368. doi: http://dx.doi.org/10.36953/ECJ.2020.21307

Saratale, G. 2012. Lignocellulosics to ethanol: The future of the chemical and energy industry. African Journal of Biotechnology, 11, 1002-1013. doi:10.5897/AJB10.897

Shengdong, Z., Ziniu, Y., Yuanxin, W., Xia, Z., Hui, L. and Ming, G. 2005. Enhancing enzymatic hydrolysis of rice straw by microwave pretreatment. Chemical Engineering Communications, 192(12), 1559-1566.

Siqueira, G., Várnai, A., Ferraz, A. and Milagres, A. M. F. 2013. Enhancement of cellulose hydrolysis in sugarcane bagasse by the selective removal of lignin with sodium chlorite. Applied Energy, 102, 399-402.

doi:https://doi.org/10.1016/j.apenergy.2012.07.029

Sluiter, A., Hames, B., Hyman, D., Payne, C., Ruiz, R., Scarlata, C., Sluiter, J., Templeton, D. and Wolfe, J. (2008a). Determination of Total Solids in Biomass and Total Dissolved Solids in Liquid Process Samples "Laboratory Analytical Procedure (LAP)". Retrieved from National Renewable Energy Laboratory, Department of Energy, Colorado, USA:

http://www.nrel.gov/biomass/analytical_procedures.html

Sluiter, A., Hames, B., Ruiz, R., Scarlata, C., Sluiter, J., Templeton, D. and Crocker, D. (2012). Determination of Structural Carbohydrates and Lignin in Biomass "Laboratory Analytical Procedure (LAP)" (NREL/TP-51042618). Retrieved from National Renewable Energy Laboratory, Department of Energy,Colorado, USA: http://www.nrel.gov/biomass/analytical_procedures.html

Sluiter, A., Ruiz, R., Scarlata, C., Sluiter, J. and Templeton, D. (2008b). Determination of Extractives in Biomass. Retrieved from Colorado, USA: http://www.nrel.gov/biomass/analytical_procedures.html

Subhedar, P. B. and Gogate, P. R. 2014. Alkaline and ultrasound assisted alkaline pretreatment for intensification of delignification process from sustainable raw-material. Ultrasonics Sonochemistry, 21(1), 216-225. doi:https://doi.org/10.1016/j.ultsonch.2013.08.001

Sun, Y. C., Liu, X. N., Wang, T. T., Xue, B. L. and Sun, R. C. 2019. A Green Process for Extraction of Lignin by the Microwave-assisted Ionic Liquid Approach: Towards Biomass Biorefinery and Lignin Characterization. ACS Sustainable Chemistry \& Engineering, 7.

Veggi, P. C., Martinez, J. and Meireles, M. A. A. 2013. Fundamentals of Microwave Extraction. In F. Chemat and G. Cravotto (Eds.), Microwave-assisted Extraction for Bioactive Compounds: Theory and Practice (pp. 15-52). Boston, MA: Springer US. 
Xiao, B., Sun, X. F. and Sun, R. 2001. Chemical, structural, and thermal characterizations of alkali-soluble lignins and hemicelluloses, and cellulose from maize stems, rye straw, and rice straw. Polymer Degradation and Stability, 74(2), 307-319.

doi:https://doi.org/10.1016/S0141-3910(01)00163-X

Yaakob, M. N. A., Bin Roslan, R., Salim, N., Binti Mustapha, S. N. H., Zakaria, S., Chia, C. H., Sajab, M. S. and Yek, P. N. Y. 2020. Effect of Temperature on the Yield of Lignin Extracted Using Microwave-Assisted Acetosolv from Empty Fruit Bunch Fibers. Materials Science Forum, 981, 240-244. doi:10.4028/www.scientific.net/MSF.981.240
Yadav, S. P., Ray, A. K. and Ghosh, U. K. 2016. Optimization of Rice Straw Acid Hydrolysis Using Response Surface Methodology. American Journal of Environmental Engineering, 6(6), 174-183. doi:10.5923/j.ajee.20160606.03

Yu, S., Sun, J., Shi, Y., Wang, Q., Wu, J. and Liu, J. 2021. Nanocellulose from various biomass wastes: Its preparation and potential usages towards the high value-added products. Environmental Science and Ecotechnology, 5, 100077. doi:https://doi.org/10.1016/j.ese.2020.100077

Zheng, Y., Zhao, J., Xu, F. and Li, Y. 2014. Pretreatment of lignocellulosic biomass for enhanced biogas production. Progress in Energy and Combustion Science, 42, 35-53. doi:https://doi.org/10.1016/j.pecs.2014.01.001 